\title{
El taller de las Poesías Sueltas de Antonio Machado. Cómo nace un soneto
}

\author{
Giovanni CaravagGi \\ Universidad de Pavía
}

Título: El taller de las Poesías Sueltas de Antonio Machado. Cómo nace un soneto.

Resumen: Este trabajo pretende estudiar el proceso creativo de las Poesías sueltas de Antonio Machado, utilizando para ello los métodos de la filología de autor. Se atiende tanto a poemas editados por el sevillano como a otros inéditos y al proyecto del autor de crear una antología cuya finalidad resulta incierta. Se profundiza asimismo en el análisis de las diversas fases de redacción del soneto "¿En dónde, sobre piedra aborrascada”.

Palabras clave: Filología de autor, Soneto, Antonio Machado.

Fecha de recepción: 5/6/2014.

Fecha de aceptación: 24/7/2014.
Title: The Workshop of Antonio Machado's Poesías sueltas. How a Sonnet Is Born.

Abstract: This article studies the creative process of the book Poesias sueltas, written by Antonio Machado, using the methodology of the "Philology Author". We contemplate the study of unpublished and published sonnets in relation with the proyect of creating an anthology, whose purpose is uncertain. We also delve into the analysis of the Machado's sonnet "¿En dónde, sobre piedra aborrascada".

Key words: Author's philology, Sonnet, Antonio Machado.

Date of Receipt: 5/6/2014.

Date of Approval: 24/7/2014.

La sección de las Poesías Sueltas (PS) de Antonio Machado comprende un conjunto bastante extenso de poemas, algunos publicados por el autor, pero no recogidos en su edición definitiva de las Poesías Completas $\left(P C^{4}\right)$, y muchos otros inéditos. La constitución del corpus de las $P S$ se relaciona estrechamente con las vicisitudes editoriales de los poemarios machadianos. El conjunto de las PS, más que un depósito de buenas intenciones, 
representa de hecho un muestrario de los incesantes sondeos del autor, de gran interés para la comprensión del proceso de sus construcciones poéticas. En efecto, una reseña de ese importante material permite evidenciar en muchos casos las diferentes fases de la elaboración de un poema como momentos sucesivos en los que se realiza el intento creativo del autor ${ }^{1}$.

La parte impresa de las $P S$ resulta bastante limitada; el núcleo más antiguo concierne a los textos de $S^{1}$ que no pasaron a $S^{2}$. Los analizó Dámaso Alonso en un estudio estilístico de extraordinaria sensibilidad ${ }^{2}$, y Cesare Segre los examinó magistralmente desde una perspectiva estructuralista ${ }^{3}$.

La sedimentación de las PS queda documentada sobre todo por una serie de cuadernos de apuntes machadianos, disponibles sólo en estos últimos años, a través de preciosas reproducciones en facsímil: Compl., $C B$ y $C S$.

Desde el punto de vista ecdótico es preciso mencionar la larga investigación de Oreste Macrí, atestiguada por tres sucesivas ediciones críticas fundamentales, $L R, E C, L T$. En ellas, la sección de las $P S$ se acrecienta gradualmente, pasando de LXII a LXXV y LXXXVI textos, respectivamente. Por otra parte, en ECA llegan a ser XCII, y en nuestra edición MO CXXVII.

Una serie importante de esbozos poéticos machadianos se conserva en un cuaderno de apuntes que el poeta, poco después de la muerte de Leonor, empezó a redactar, más o menos en forma de diario, con el título Los Complementarios (el mismo título lo debía atribuir más tarde a una de las obras apócrifas de Abel Martín). Este precioso autógrafo se conserva hoy en la Biblioteca Nacional de Madrid (ms. Res. 275), que lo compró en 1967 a los herederos del poeta; se realizó poco después una reproducción facsímil de buena calidad, Compl., acompañada por una edición crítica apreciable. Algo más arbitraria, aunque no carente de justificación, es la edición ofrecida por Alvar, que organiza los diferentes apuntes ma-

1 Véase Gianfranco Contini, Varianti e altra linguistica, Turín, Einaudi, 1970.

2 Dámaso Alonso, "Poesías olvidadas de Antonio Machado", en Obras Completas, Madrid, Gredos, 1975, IV, pp. 594-645.

3 Cesare Segre, "Sistema y estructura en las Soledades de Antonio Machado", en Critica bajo control, Barcelona, Planeta, 1970, pp. 103-150 (traducción aumentada de I segni e la critica, Turín, Einaudi, 1969). 
chadianos según sus categorías temáticas ${ }^{4}$. Hubiera sido más oportuno, probablemente, respetar la secuencia textual del autógrafo, evidenciando las relaciones entre sus diferentes temáticas mediante un índice analítico pormenorizado.

Una cantidad impresionante de esbozos poéticos se conserva además en varios cuadernos de apuntes machadianos, inéditos hasta estos últimos años, y ahora felizmente recuperados, es decir, los $C B$ y los $C S$.

En realidad, ya desde mucho tiempo se conocía la existencia de unos cuadernos de Antonio Machado que, acabada ya la Guerra Civil, pasaron a la casa de su hermano Manuel (los acontecimientos bélicos, como bien se sabe, habían separado definitivamente a los dos hermanos); a la muerte de Manuel, doña Eulalia Cáceres, su viuda, quizás preocupada por el contenido "herético" de algunas reflexiones filosóficas y políticas contenidas en aquellos borradores, los confió en 1948 a un ilustre sacerdote de Burgos, don Bonifacio Zamora Usábel (1901-1989), su padre espiritual y socio fundador de la "Institución Fernán González. Academia Burgense de Historia y Bellas Artes"; este conservó prudentemente, durante casi treinta ańos, todos aquellos manuscritos, y acabada ya la dictadura franquista, los donó en 1977 a dicha Institución. El proyecto de edición crítica, a cargo de Oreste Macrí y Gaetano Chiappini, quedó interrumpido a la muerte del ilustre maestro de la Universidad de Florencia.

La conservación del material es, en general, bastante buena, pero muchas páginas fueron arrancadas (probablemente por el poeta mismo), y actualmente sobreviven de ellas tan solo estrechas tiras, con sendas muestras de escritura.

Los preciosos autógrafos (siete cuadernos y muchas hojas sueltas) fueron catalogados por manos diferentes y en tiempos sucesivos, no siempre de manera coherente. No se sabe quién ha sido el responsable del orden (o desorden) actual de las hojas sueltas, pero en concreto es inevitable ahora la referencia a su colocación definitiva en la esmerada reproducción facsímil de $C B$.

Otros importantes borradores poéticos se conservan en unos cuadernos machadianos que doña Eulalia Cáceres dejó en manos de Francisco

4 Antonio Machado, Los Complementarios, ed. Manuel Alvar, Madrid, Cátedra, 1982 ( $2^{\mathrm{a}}$ ed.). 
Machado, el hermano menor del poeta (1884-1950); el 20 de noviembre de 2003 las sobrinas del poeta los cedieron a Unicaja de Málaga, en una subasta organizada por el Centro Cultural El Monte de Sevilla. Apareció pronto una valiosa reproducción facsímil, $C S$, acompañada de una transcripción, a veces demasiado apresurada, y un breve comentario.

Obviamente no todo el material recuperado presenta el mismo valor documental. Algunos cuadernos de apuntes, los así llamados "cuadernos de trabajo", no tienen un gran interés desde el punto de vista literario y se deben a circunstancias ocasionales; entre los $C S$ se incluyen, por ejemplo, un cuaderno de Teoría de la aritmética y uno de Aritmética mercantil (o Matemática financiera), serie de apuntes probablemente anteriores a 1906, cuando Antonio Machado pensaba presentarse a una oposición para un empleo en el Banco de Espańa; además se conserva un Programa de Lengua francesa, fechado Soria. 1910 - 1911 y relativo al curso de lengua dictado por el poeta, con ejercicios prácticos y notas bibliográficas; y también se encuentra un conjunto de apuntes de Historia de España, desde Fernando IV hasta Felipe V, con una breve premisa sobre la prehistoria; se trata de apuntes de corte manualístico, quizás reunidos hacia 1915; y la misma tipología presentan los de otra serie análoga, desde Felipe V hasta Napoleón, con observaciones sobre la Primera Guerra Mundial y consideraciones igualmente genéricas. No mucho más original resulta el cuaderno de apuntes de historia de la literatura espańola, desde Diego Hurtado de Mendoza hasta Luis Vélez de Guevara, sacados de la traducción francesa de un conocido manual escolar"

Por su parte, el fondo de Burgos conserva un "cuaderno de trabajo" más o menos de 1916: Besteiro 2\% / Apuntes. / Filosofía; se trata de apuntes de filosofía reunidos en función del examen que Machado debía sostener con el Prof. Julián Besteiro (1870-1940), “catedrático” de Lógica en la Complutense y personaje de gran talla moral: se había formado en la INSTI y había profundizado sus estudios en Alemania; en 1917 fue expulsado de la Universidad por su apoyo a la huelga general de la UGT, pero poco después fue reintegrado en su cargo; de 1913 a 1936 fue diputado del PSOE y en 1931 Presidente de las Cortes; al final de la Guerra Civil padeció el encarcelamiento.

5 Concretamente de James Fitzmaurice-Kelly, Littérature espagnole, París, Armand Colin, 1913, $2^{\text {e }}$ éd. refondue et augmentée. 
La parte más significativa de los $C B$ y de los $C S$ contiene esbozos y variantes de textos poéticos éditos e inéditos que exigen un análisis filológico profundizado, sobre todo en clave ecdótica; en un millar de hojas se concentra en efecto la historia del proceso creativo de muchos poemas machadianos, especialmente los de la época de Baeza y Segovia (19121919 y 1919-1931), cuando se efectuó una evolución profunda del sistema poético del autor, a través de una serie de experimentaciones complejas. En cuanto concierne a los textos en prosa, es de interés considerable el estudio que Chiappini publicó hace un par de décadas ${ }^{6}$.

En el caso específico de la creación de los sonetos, el conjunto de los autógrafos machadianos que se conserva en dichos cuadernos ofrece a la investigación una serie abundante de testimonios fundamentales.

Como es notorio, la estructura del soneto, con su rigor formal, impone a cada autor un ejercicio compositivo complejo, que a veces se logra documentar en sus fases sucesivas.

Antonio Machado es autor de unos cuarenta sonetos (incluyendo los apócrifos, los inéditos y los que se le atribuyen), sean de tipo clásico, sean modernistas, todos de calidad apreciable; no se trata de una producción juvenil, porque ninguno de ellos se publica en $P C^{1}$; de los 24 publicados en $P C^{4}, 19$ se concentran en Nuevas Canciones (casi todos con carácter autobiográfico), y más concretamente 14 en CLXIV, Glosando a Ronsardy otras rimas, y 5 en CLXV, con el título genérico: Sonetos; otros 5 se reúnen en el Cancionero Apócrifo, CLXVII, VIII, IX, X, XI, XV, con atribución a Abel Martín; entre los 16 de PS destacan los 9 compuestos durante la Guerra Civil, sólo en parte encomiásticos; deben excluirse por supuesto los tres de Juan Alcaide Sánchez que comparecen sin nombre de autor en $C b, H s$, ff. 5, 11 y 12 . También son de interés.

El estudio de los esbozos autógrafos deja ver que el poeta intenta recuperar este rígido molde compositivo durante los ańos de Baeza, "pasando por Ronsard" (como declara él mismo), y por los poetas españoles del Renacimiento y del Barroco (como también consta). La redacción de los sonetos más antiguos se remonta a finales de 1912 o comienzos de 1913, aunque es posible recuperar unos esbozos anteriores (desde 1907); la de

6 Gaetano Chiappini, "Intorno alle prose edite e inedite di Antonio Machado nei manoscritti di Burgos", en Antonio Machado hacia Europa, ed. Pablo Luis Ávila, Madrid, Visor, 1990, pp. 97-104. 
los nueve últimos pertenece, como se ha dicho, a los años de la Guerra Civil y se coloca entre 1937 y 1938.

En los primeros meses de su estancia en Baeza, el poeta empieza a desarrollar también una reflexión histórico-crítica sobre el soneto, como se deduce de los apuntes iniciales de los Compl. (ff. 3v-6r), que incluyen además una reducida muestra antológica, con fecha "Sevilla 1913". Machado transcribe en primer lugar (f. 3v), bajo el título Un soneto de Dante, el soneto XII de la Vita Nuova, "Amor e 'l cor gentil sono una cosa", añadiendo en el margen derecho, de abajo arriba, dos observaciones lapidarias, "concepto y poesía" y "no hay sonetos románticos"; al lado del texto, en columna, injerta un comentario algo más articulado:

Va el soneto desde lo escolástico a lo barroco. De Dante a Góngora, pasando por Ronsard. No es composición moderna, a pesar de Heredia. La emoción del soneto se ha perdido. Queda sólo su esqueleto, demasiado sólido y pesado, para la forma lírica actual. Todavía se encuentran algunos buenos sonetos en los poetas portugueses. En España son bellísimos los de Manuel Machado. Rubén Darío no hizo ninguno digno de mención.

A pesar del juicio final, demasiado restrictivo, resulta muy interesante ese intento de definir una perspectiva diacrónica del desarrollo del soneto, en cuanto subgénero poético.

A continuación, el poeta reproduce en efecto otros cuatro sonetos ejemplares, de Ronsard ("Doux fut le trait, qu'amour hors de sa trousse"), Lope de Vega ("Suelta mi manso, mayoral extraño”), Góngora ("Esta forma elegante, oh peregrino") y de su propio hermano Manuel ("Hierática visión de pesadilla"), acompañados por definiciones sintéticas; y acaba la pequeña antología con uno suyo (PC, CLXIV, XV, II, “¿Porqué, decisme, hacia los altos llanos"), sin comentario específico, pero dejando abierta la perspectiva con una nota aislada, bastante genérica: "más documentos que utilizar" (f. 6r). Lo que le parecía oportuno documentar se relaciona probablemente con un proyecto antológico de mayor envergadura, del cual no quedan noticias precisas; pero quedan trazas muy concretas de aquel en las páginas de los Compl., porque de una extremidad a otra del cuaderno se extiende una selección de sonetos españoles y extranjeros (so- 
bre todo franceses e ingleses), copiados más o menos durante una década, desde marzo de 1913 hasta noviembre de 1924.

Se puede notar por tanto la continuidad cronológica del intento y también su dimensión imponente; a partir del f. 9v se suceden, esporádicamente pero con cierta insistencia, las reproducciones de una decena de textos, escogidos indudablemente por su carácter representativo, que en el conjunto forman una colección significativa; merece la pena mencionarlos, con la fecha aproximada de su transcripción, como muestra de los intereses literarios y estéticos del poeta:

- f. 9v, Góngora, "Bien dispuesta madera en nueva traza" (marzo-abril de 1914).

- f. 21r, Góngora, "Cosas, Celalba mía, he visto extrañas" (diciembre de 1915 - febrero de 1916).

- f. 30v, Lope de Vega, “¿Qué tengo yo, que mi amistad procuras?” (septiembre-octubre de1917; vuelto a copiar en el f. 126v, más o menos en setiembre de 1923).

- f. 41r, Quevedo, “Buscas en Roma a Roma, joh peregrino!” (durante 1920).

- f. 41v, Quevedo, "Faltar pudo su patria al Grande Osuna” (durante 1920).

- f. 78v, Fray Luis de León (con nota: Un fray Luis Ronsardiano), "Agora con la aurora se levanta" (abril-octubre de 1922).

- f. 170v, Góngora, "De ríos soy el Duero acompañado" (durante 1924).

- f. 172v, Fernando de Herrera, "En sortijas y flores de oro ardiente" (durante 1924).

- f. 178r, Góngora, "Deste más que la nieve blanco toro" (durante 1924).

- f. 180v, Góngora, "Vive en este volumen el que yace" (durante 1924).

Pero la selección machadiana se extiende también a textos pertenecientes a otras literaturas; en efecto, en Compl. se transcriben un soneto de Camôes (f. 100r), cuatro de Shakespeare (f 118r-119v y 176v), tres de Paul Valéry (ff. 154v, 155r y 179r), uno de Paul Verlaine (f. 181v) y tres (en francés) de José María de Heredia (ff. 187v-188v). 
No resulta muy clara la finalidad de esa antología de sonetos, que podía tener un valor estrictamente personal o favorecer alguna aplicación didáctica (muy en el estilo de Juan de Mairena); es menos probable que pudiese relacionarse con algún destino editorial específico.

Lo que, al contrario, parece bastante probable es que Machado hacia 1924 tuviese la intención de publicar separadamente sus propios sonetos, porque en el centro del f. 136r de los Compl. comparece, casi en forma de frontispicio, el proyecto siguiente:

Sonetos.

(1924).

Antonio Machado;

y en el f. 136r, después de un breve comentario estético, muy personal, se anuncian los criterios, más bien temáticos que cronológicos, que debían adoptarse en la composición del "libro":

El encadenamiento de la rima de los cuartetos [es] la condición, según los preceptistas, esencial de la estructura del soneto. Yo no lo creo así. Por el contrario, la independencia de los cuartetos ańade gran belleza al soneto.

Van anotados por orden cronológico.

Pero en el libro deberán agruparse según los temas.

En un momento sucesivo (la grafía es bastante diferente), se añade un plan esquemático, que modifica dicho proyecto, extendiéndolo de manera considerable:

\section{Sonetos \\ 10 Canciones \\ 30 Proverbios}

En el margen de la derecha, verticalmente de arriba abajo, figura la nota: "Inéditos hasta la fecha"; y la fecha se coloca al pie de la página: "Madrid, 20 Junio 1924". Se desconoce el contenido concreto de este nuevo "libro". Sin duda, 25 sonetos constituyen una entidad poética de cierta relevancia; las $N C$ habían aparecido ya hacía un par de meses (el colofón 
de la princeps lleva la fecha del 22 de abril de 1924); cabe suponer que no pocos de ellos, aún inéditos a mediados de 1924, confluirían en las sucesivas ediciones de $P C$. Por ejemplo, podían pertenecer a ese conjunto los cinco de CLXV, que faltaban en $N C$, se publicaron en Alfar, V, 52, septiembre de 1925, y se integraron en Nuevas Canciones a partir de $P C^{2}$; otros pudieron incluirse en el Cancionero Apócrifo; algunos debieron de quedar inéditos.

El proyecto de reagrupación que se estaba constituyendo deja otra traza, al comienzo de 1925, en unas hojas sueltas de CS.

Cuando se estaban acabando, en 1925, las páginas de los Compl., en el f. 200r, ocupándolo enteramente, aparece una interesante nota de remisión a otro cuaderno de apuntes:

Copia de los borradores de / poesías / inéditas (1917-1924) o no incluidas en volumen y contenidas $/$ en este cuaderno $=$ Pasan al cuaderno $3^{\circ}$.

El cuaderno $3^{\circ}$ no se ha salvado integralmente; sobreviven solo 27 hojas arrancadas, que se conservan en $C S, H S$, ff. $18 \mathrm{r}-44 \mathrm{v}$. En la primera (f. 18r) figuran entre paréntesis dos reagrupaciones nuevas, indicadas con definiciones helenizantes, y una fecha:
(Parergon).
(Paralipómenos).
Madrid
1925

En la sucesiva (f. 19r) aparecen unas Notas explicativas, que clasifican los textos inéditos, indicando su cronología específica a través de unos signos marcadores distintos; y entre paréntesis vuelven a utilizarse las definiciones de origen griego ya anunciadas, cuyo sentido queda así aclarado:

\section{Poesías}

+ (Composiciones escritas entre 1912 y 1924 y que no han sido incluidas en los volúmenes publicados por el autor, hasta la fecha). + (Paralipómenos). 
(1) (Composiciones escritas después de la publicación de "Nuevas Canciones".) (1) (Parergon).

(..) (Algunas composiciones publicadas en diversa forma que la transcripta en este cuaderno). Borradores de composiciones corregidas y correcciones a primeras redacciones.

Notas.

Y en el f. 20r, otra vez en forma de frontispicio, se anuncia por fin la siguiente agrupación textual

\section{Sonetos}

(Escritos entre 1912 y 1917)

Se trata de nueve sonetos, copiados en limpio (pero con algunas correcciones), repartidos en los ff. 21r-29r, cada uno en el recto de una hoja, casi todos fechados; todos marcados con + (es decir, escritos antes de 1924 pero no publicados), menos uno, marcado con (1) (es decir posterior a $N C$ ), según el prospecto siguiente:

1) f. 21r: "Y nunca más la tierra de ceniza" $\quad+1912$

2) f. 22r: "Verás la maravilla del camino" + +1912

3) f. 23r: "Huye del triste amor, amor pacato" $\quad+1912$

4) f. 24r: "Tuvo mi corazón encrucijada" +

5) f. 25r: "El tiempo que la barba me platea" +

6) f. 26r: "Esta luz de Sevilla...Es el palacio" (1) 1924

7) f. 27r: “¿Empañé tu memoria? ¡Cuántas veces!” + 1912-1918

8) f. 28r: “¿En dónde, sobre piedra aborrascada" + +1918

9) f. 29r: "Nubes, sol, prado verde y caserío" + $\quad+1918$

Pocos meses más tarde, en septiembre de 1925, cinco de ellos (los $\mathrm{n}^{\text {os. }}$ 2, 3, 4, 6, 7) se publicaron en Alfar, V, 52, con orden distinto, pasando después a $P C^{2}$, como se ha recordado arriba, y dos (los $\mathrm{n}^{\text {os. }} 5$ y 9$)$ se incorporaron en el Cancionero Apócrifo de Abel Martín, respectivamente con el título Guerra de amor (CLXVII, X) y Primaveral (CLXVII, VIII). Los dos restantes (los $\mathrm{n}^{\text {os. }} 1$ y 8 ), como se sabe, no se recogieron en $P C^{4}$. De cada soneto se conservan redacciones diferentes, con variantes a veces muy significativas. En los cuadernos de apuntes quedan trazas de su progresiva 
elaboración, de las íntimas vicisitudes de su génesis, a través de esbozos más o menos acabados. En algunos casos se trata de una historia bastante sencilla, en otros algo más compleja, y siempre de gran interés en la percepción fenomenológica de la dimensión dinámica del texto, considerado en sus distintos momentos creativos ${ }^{7}$, según la perspectiva neolachmanniana, magistralmente definida por Contini, "che riunisce per cosí dire gli incunaboli del metodo, tra i contributi più originali della cultura italiana al pensiero critico moderno. Se ne spiega bene perché da noi più che altrove l'ecdotica di testi in fieri o in redazioni plurime sia stata e continui ad essere assai fervida"

Por ejemplo, el soneto “¿En dónde, sobre piedra aborrascada”, uno de los que Machado no quiso publicar, conoció un proceso redaccional largo y complejo, antes de realizarse definitivamente.

En Compl. f. 181r se conserva una redacción casi en limpio, a pesar de muchas tachaduras de tinta y unas cuantas correcciones:

¿En dónde, sobre piedra aborrascada, vieja ciudad de pardo caserío te he visto, y entre montes empinada? Al fondo de un barranco suena un río.

¿Vieja ciudad, la luna amoratada asoma, enorme, en el azul vacío sobre la fortaleza torreada? ¡Oh ruina familiar de un sueño mío!

Mas esos claros chopos de ribera - ¡cual vence una sonrisa un duro ceño!me tornan a un jardín de primavera, gonces del sueńo, al verdear risueño. ¡Rosa carmín y blanca arrebolera también salís del fondo de mi sueño.

Las enmiendas no tienen un valor particularmente significativo; en el v. 5 "Vieja ciudad" ha sido corregido bajo algunas palabras tachadas (parece posible leer "Y esas horas con luna amoratada"); en el v. 6 se leía "que aso-

7 D’Arco Silvio Avalle, Principi di critica testuale, Roma, Antenore, 2002², p. 33.

8 Dante Isella, Le carte mescolate vecchie e nuove, a cura di Silvia Isella Brusamolino, Turín, Einaudi, 2009, p. 29. 
ma", pero el relativo ha sido tachado; en el v. 7 el artículo de "la fortaleza" ha sido corregido sobre un posesivo tachado ("tu fortaleza"); en el v. 14 "salís" se ha repetido bajo una palabra cubierta por tachaduras (quizás la misma). A pie de página comparecen la sigla del poeta y dos fechas:

\section{A.M. / 1907 = copiada en 1924 .}

En 1907 no debía existir todavía el soneto, pero es probable que a ese período puedan remontarse algunos apuntes líricos que se examinarán en seguida.

En $C S, H S$, f. 28r., como ya se ha indicado, comparece una copia en limpio, realizada en 1925 y fechada en 1918 , con puntuación incompleta y las variantes siguientes:

3. te he visto, y entre montes levantada

5. Vieja ciudad! ... La luna amoratada

7. sobre tu fortaleza torreada

11. me tornan mi rincón de primavera.

A pesar de la fecha de transcripción, la tipología de las variantes parece indicar no tanto una refundición definitiva del texto, sino más bien una fase intermedia, porque se reflejan aquí soluciones típicas de algunos esbozos rechazados.

Una redacción incompleta del soneto, más o menos del año 1924, totalmente tachada pero recuperable, figura en Compl., f. 179v:

En donde sobre piedra aborrascada, vieja ciudad de pardo caserío, te he visto, y entre montes empinada, ¡oh ruina familiar de un sueño mío! ¡Vieja ciudad! La luna amoratada asoma, enorme, en el azul vacío sobre tu fortaleza torreada!

Al fondo de un barranco suena un río. ¿Por qué es allí donde la primavera puso la rosa de carmín un día

y una noche la blanca arrebolera? 
Aquí el soneto todavía no se ha realizado integralmente, pero los cuartetos ya tienen una estructura casi definitiva; destaca en esta fase de su elaboración la inversión de los versos 4 y 8, que desde luego, siendo aislados sintácticamente al final de sus respectivos núcleos estróficos, resultan intercambiables con relativa facilidad. Después del v. 4 el poeta había copiado un verso, "Sobre tu fortaleza torreada", que tachó enseguida, para recuperarlo poco después en el v. 7; en el v. 11 "arrebolera" se lee con cierta dificultad. Indudablemente, la presencia de un terceto carente de su pareja suscita la sensación de una estructura que se está construyendo gradualmente; destacan en esta fase los componentes enfáticos.

La primera fase redaccional podría remontarse hasta el año 1907, si se considera la fecha ya mencionada de Compl. f. 181r.

En $C S, H S$, f. $42 \mathrm{r}$ se conserva una cuarteta aislada, sin indicaciones de composición (en el v. 3 no me parece aceptable la lectura: "lo he visto" que se sugiere en la ed. cit., p. 309):

En dónde, sobre piedra aborrascada, vieja ciudad de pardo caserío te he visto, y entre montes empinada. Al fondo del barranco sueña un río.

De manera contrastiva se añade, en esta hoja, el curioso esbozo de una redacción octosilábica del mismo motivo, una copla que en realidad no ha conocido desarrollos sucesivos:

Entre piedra aborrascada

con tu pobre caserío,

vieja ciudad asomada

sobre el barranco del río.

Se notan aquí algunas correcciones: en el v. 1 "Entre" escrito encima de "Sobre" tachado; después del v. 1, figura el comienzo del v. 4, tachado, "sobre el barr"; en el v. 3 "asomada" corregido bajo el comienzo de una palabra tachada, "enpina $[d a]$ ". Se suceden, por tanto, dos exordios que en su contraste formal llamativo podrían indicar distintos sondeos en las direcciones opuestas de la lírica clásica y del canto popular. Considerado 
el tipo de papel, esta hoja suelta podría haber sido arrancada del cuaderno de apuntes ya mencionado, que Machado designaba como "cuaderno $3^{\circ \text { ". }}$

Pero es el actual CS. 3 el que permite reconstruir más detenidamente el proceso redaccional del texto, a partir del f. $1 \mathrm{v}$, donde se presenta una sucesión de seis versos, en limpio pero casi totalmente carentes de puntuación; podrían representar la versión antigua de un primer cuarteto, con el comienzo del segundo:
vieja ciudad de pardo caserío
donde te vi entre montes levantada
oh ruina familiar de un sueño mío
En tu cielo la luna amoratada
asoma, enorme, en el azul vacío
sobre tu fortaleza torreada.

En el f. $2 \mathrm{r}$ del mismo cuaderno sigue de inmediato un conjunto de 11 versos, donde escasea la puntuación y se distinguen sin dificultad dos cuartetos y un terceto; es decir, el esbozo de un soneto que aún no logra realizarse:

En dónde, sobre piedra aborrascada, vieja ciudad de pardo caserío te he visto, y entre montes empinada. $\mathrm{Al}$ fondo del barranco suena un río.

En tu cielo la luna amoratada asoma, enorme, en el azul vacío sobre tu fortaleza torreada oh ruina familiar del sueño mío

Oh viejo nido de mi vieja raza, siempre aguardando el beso de la luna, casi desnudo en tu desierta plaza.

No me parece correcta en el v. 10 la lectura "campo aguardando" de la ed. cit., p. 29. Los cuartetos están consiguiendo ya un estatuto casi definitivo, mientras el terceto, otra vez sin su pareja, resulta totalmente distinto del que se ha considerado arriba. El poeta, pues, sigue buscando una conclusión satisfactoria. 
Entre los cuartetos quedan trazas de un dístico, que ha sido tachado y no es recuperable con certeza:
O como hielo (?) hundida por la (.... ) de una mano.

Me parece dudosa la reconstrucción propuesta en la ed. cit., p. 29:
O como huella hundida
por la rasa sorpresa [?] de una mano.

En el f. 3 r figuran solamente tres palabras iniciales, "Donde, ciudad de", que remiten al comienzo del f. $4 \mathrm{r}$, donde se redactan dos cuartetos, en limpio, con puntuación muy incompleta y variantes notables:

¿Dónde, ciudad de pardo caserío te he visto, y entre montes empinada?

Oh ruina familiar de un sueño mío, sobre tu fortaleza torreada asoma, enorme, en el azul vacío el globo de una luna amoratada al fondo del barranco suena el río que corre entre la piedra aborrascada.

Redactada con cierta prisa, esa nueva versión representa más bien el desarrollo de la que aparecía en el f. $1 \mathrm{v}$, porque conserva el mismo sistema de alternancia de las consonantes -io / -ada, pero completando el segundo cuarteto; no se trata, sin embargo, de un cambio definitivo, en cuanto ese esquema será pronto rechazado, como evidencia el cotejo con el texto que se encuentra en el f. 6r, una sucesión de trece versos de gran interés ecdótico, los 11 primeros totalmente borrados con largos rasgos verticales y oblicuos, los dos finales en limpio, separados por un espacio:

¿En dónde, sobre piedra aborrascada, vieja ciudad de pardo caserío te he visto, y entre montes empinada? $\mathrm{Al}$ fondo del barranco suena un río. 
La luna amoratada

asoma, enorme, en el azul vacío

sobre tu fortaleza torreada.

Oh ruina familiar de un sueño mío

No eres Soria, Sepúlveda o Pedraza, cuna imperial o pobre cual ninguna, ciudad, desierto nido de una raza.

Oh sólo queda en tu desierta plaza el olmo corpulento.

Los cuartetos vuelven a proponer aquí, en sus rasgos fundamentales, la misma estructura que se presentaba en el f. 2 r, pero el quebrado del v. 5 parece manifestar aún alguna indecisión, mientras el terceto, notablemente renovado, queda otra vez aislado; sin embargo, en los versos ańadidos en el final, empieza a esbozarse el comienzo de su pareja; pero el soneto no ha logrado completarse ni siquiera en esta fase.

Lo que parece faltar aún es la debida relación dialéctica entre cuartetos y tercetos; permite comprobarlo también el esbozo sucesivo, que se conserva en el f. $7 \mathrm{r}$; consta de dos cuartetos en limpio (pero con el v. 8 tachado), más una serie fragmentaria de apuntes y versos, completamente tachada:

En dónde, sobre piedra aborrascada, vieja ciudad de pardo caserío te he visto, y entre montes empinada. Oh ruina familiar de un sueño mío.

Vieja ciudad! La luna amoratada asoma, enorme, en el azul vacío sobre tu fortaleza torreada.

Al fondo del barranco suena un río.

En estos cuartetos, los vv. 4 y 8 se han intercambiado; se anticipa así la nota enfática, que prevalece sobre la descriptiva. Lo que sigue es un conjunto bastante heterogéneo de fragmentos de versos, apuntes de carácter lingüístico y un nuevo esbozo de tercetos, todavía sin perfeccionar. 
Allí vives, mujer,

roblizo $=$ recio $=$ fuerte $=$

Oh río

Allí, mujer, de tu palacio brilla, en la desierta plaza, la vidriera, de la ventana con una blanca luz de pesadilla, con una $[$.... allí se asoma en la tarde una monda calavera

Más adelante, en el f. 19r, vuelven a repetirse los cuartetos ya considerados, con mínimas diferencias en el relieve enfático:

¿En dónde, sobre piedra aborrascada, vieja ciudad de pardo caserío te he visto, y entre montes empinada? Oh ruina familiar de un sueño mío.

Vieja ciudad. La luna amoratada asoma, enorme, en el azul vacío sobre tu fortaleza torreada. Al fondo del barranco sueña un río.

Y por fin, en el f. 52r, bajo la rúbrica shakespeariana "To be or not to be that is the question", se repite el primer cuarteto, sin interrogantes:

En dónde, sobre piedra aborrascada, vieja ciudad de pardo caserío, te he visto, y entre montes empinada. Oh ruina familiar de un sueño mío.

Sucesivamente, acabado ya el problemático soneto, el poeta lo transcribe, hacia 1925, en la serie de $C S, H S$, que se ha examinado más arriba, pero no lo quiere colocar entre los que publica en Alfar, V, como ya se ha notado. 
Sin embargo, esa vicisitud redaccional, tan atormentada y compleja, no debía concluirse con un inédito, porque pocos meses más tarde, en la misma revista poética (Alfar, VI, 55. 1925-1926), dentro de una doble serie de Apuntes líricos para una geografía emotiva de España (fechados en 1925; este título sobrevive en el Cancionero Apócrifo: cfr. CLXXI), Machado incluye también los dos cuartetos que tantas veces había vuelto a elaborar, pero deja todavía incompleto el v. 5:
¿En dónde, sobre piedra aborrascada, vieja ciudad de pardo caserío, te he visto, y entre montes empinada? En la rota muralla, el viento frío.
La luna amortajada asoma, enorme, en el azul vacío sobre la fortaleza torreada.
Al fondo del barranco suena el río.

Destacan pues, en esta conclusión del proceso creativo, la renovación completa del v. 4, y además la eliminación definitiva de la nota enfática, con un desarrollo ulterior del impresionismo descriptivo. 


\section{Abreviaciones}

$S^{1}$ Soledades, Madrid, Imprenta de A. Álvarez, 1903 (pero colofón 1902). $S^{2}$ Soledades, Galerías, Otros Poemas, Madrid, Biblioteca Hispanoamericana-Librería de Pueyo, 1907.

CC Campos de Castilla, Madrid, Renacimiento, 1912.

NC Nuevas Canciones, Madrid, Mundo Latino, 1924 (fecha del colofón: 22 de abril)

PC Poesías Completas. PC Madrid, ed. Residencia de Estudiantes, 1917; $P C^{2}$ Madrid, Espasa Calpe, 1928; $P C^{3}$ Madrid, Espasa Calpe, 1933; $P C^{4}$ Madrid, Espasa Calpe, 1936.

PS Poesías Sueltas.

Compl. A. Machado, Los Complementarios, ed. Domingo Ynduráin, Madrid, Taurus, 1971.

CB El fondo machadiano de Burgos / Los papeles de Antonio Machado, Burgos, Institución Fernán González - Academia Burgense de Historia y Bellas Artes, introd. y coord. Alberto C. Ibáñez Pérez, Digitalización de textos e imágenes Ma Pilar Alonso Abad, 2004, 2 vol. Incluyen con HS las hojas sueltas.

CS Manuscritos de los Hermanos Machado, (colección Unicaja), ed. Rafael Alarcón Sierra, Pablo del Barco y Antonio Rodríguez Almodóvar, Málaga, Servicios de Publicaciones de la Fundación Unicaja, 2006, 10 vols. Incluyen con $H S$ las hojas sueltas.

LR Poesie di Antonio Machado, ed. Oreste Macrì, Milán, Lerici, 1969 (3a ed.).

EC Antonio Machado, I. Poesías Completas; II. Prosas Completas, ed. crítica de Oreste Macrì, Madrid, Espasa Calpe-Fundación Antonio Machado, 1988 (Edición del cincuentenario).

LT Antonio Machado, Opera poetica, ed. Oreste Macrì, Florencia, Le Lettere, 1994.

ECA Antonio Machado, Poesías Completas, ed. Manuel Alvar, Madrid, Espasa Calpe, 2007 (5 a ed.).

MO Antonio Machado, Tutte le poesie e prose scelte, ed. Giovanni Caravaggi, Milán, Mondadori, 2010. 